\title{
Prevalence of Hypertension and Associated Factors in Patients Living with HIV Followed at the Ambulatory Treatment Center (CTA) of Fann National University Hospital in Dakar
}

\author{
Ndeye Fatou Ngom Gueye1,2,3, Daye Ka ${ }^{2}$, Alioune Badara Tall3, Kine Ndiaye ${ }^{1,2}$, \\ ${ }^{1}$ Ambulatory Treatment Center, Fann University Teaching Hospital, Dakar, Senegal \\ ${ }^{2}$ Department of Infectious Diseases, Fann University Teaching Hospital, Dakar, Senegal \\ ${ }^{3}$ Department of Community Health, Alioune Diop University, Bambey, Senegal \\ Email: ndeyetouti98@gmail.com
} Abdoul Aziz Ndiaye ${ }^{3}$, Viviane Marie Pierre Cisse ${ }^{2}$, Aissata Guindo², Ndeye Méry Dia Badiane ${ }^{2}$, Sylvie Audrey Diop², Noel Magloire Manga², Cheikh Tidiane Ndour², Moussa Seydi2

How to cite this paper: Gueye, N.F.N., Ka, D., Tall, A.B., Ndiaye, K., Ndiaye, A.A., Cisse, V.M.P., Guindo, A., Badiane, N.M.D., Diop, S.A., Manga, N.M., Ndour, C.T. and Seydi, M. (2017) Prevalence of Hypertension and Associated Factors in Patients Living with HIV Followed at the Ambulatory Treatment Center (CTA) of Fann National University Hospital in Dakar. Health, 9, 727737.

https://doi.org/10.4236/health.2017.94052

Received: January 3, 2017

Accepted: April 27, 2017

Published: April 30, 2017

Copyright ( 92017 by authors and Scientific Research Publishing Inc. This work is licensed under the Creative Commons Attribution International License (CC BY 4.0).

http://creativecommons.org/licenses/by/4.0/

\begin{abstract}
Introduction: The efficacy of antiretroviral therapy in people living with HIV (PLHIV) has been associated with an important increase in metabolic disorders, such as hypertension (HTA). This work allowed us to estimate the prevalence of hypertension in PLHIV and to describe associated factors. Methods: A retrospective, descriptive and analytical study was carried out based on the records of people living with HIV followed at the Ambulatory Treatment Center (CTA), from January $1^{\text {st }} 1998$ to $31^{\text {st }}$, December 2014 . The WHO criteria were used to diagnose hypertension. Data entry was performed using ESOPE software and data analysis was done using Epi Info software version 3.5.3. A multiple logistic regression was used to identify the risk factors associated with hypertension. Results: During the study period, 3624 patients followed at CTA were included of which 1184 patients (32.7\%) had hypertension. The average age was 47.3 years \pm 10.5 years, with a sex ratio of 0.7 . The most common opportunistic infections at diagnosis were tuberculosis (14.9\%) and oral candidiasis (15.3\%). The HIV infection was advanced (stage 3 or 4 of WHO classification) for $39 \%$ of cases. Overweight and obesity was found in $19.1 \%$. Only $17.6 \%$ were treated by protease inhibitors. Higher average age (OR:1,05; IC[1.04 - 1.05], $\mathrm{p}=0.000001)$, higher average BMI (OR:5,3; IC [3.3 $8.5], \mathrm{p}=0.00001)$, WHO clinical stage I-II (OR:1,4; IC $[1.2-1.6], \mathrm{p}=$ 0.00003), and ARV treatment (OR:2,5; IC [1.7 - 3.7], $\mathrm{p}=0.000001)$ are associated with the occurrence of hypertension. Conclusion: The prevalence of hypertension was high among PLHIV and associated factors were: advanced age, high BMI, WHO clinical stages I and II and antiretroviral therapy. Hence, the interest of a systematic screening of hypertension and others cardiovascu-
\end{abstract}


lar risk factors particularly in patients under ARV antiretroviral therapy.

\section{Keywords}

Hypertension (HTA), HIV Infection, Senegal

\section{Introduction}

Hypertension is a major public health problem [1]. His prevalence is currently estimated by WHO at $26.4 \%$ of adults' population in the world and $29.2 \%$ are expected to be so by 2025 . This represents a population of nearly 1.6 billion people [2] [3]. The high prevalence of hypertension in the world is also related to the progressive aging of the population, especially in Western countries, but also to the global trend of overweight and obesity in developing countries [2]. Hypertension is one of the major risk factors for cardiovascular mortality and morbidity, particularly in PLHIV. Few studies with discordant results have addressed the relationship between hypertension, HIV infection, and antiretroviral therapy. Some studies agree that the incidence of hypertension increases after the second year on highly active antiretroviral therapy introduction. They directly incriminate the side effects of ARV treatment-insulin resistance, lipodystrophies in the genesis of hypertension [4]. The later studies have concluded that there may not be any argument for a specific hypertensive and independent effect of treatment (Protease Inhibitor (PI) especially) due to the frequent presence of other cardiovascular risk factors including age, sex, BMI, smoking, dyslipidemia.

The prevalence of hypertension in HIV-infected individuals in industrialized countries ranges from $5.2 \%$ to $34.2 \%$ and is associated with antiretroviral treatment [4] [5] [6].

Many factors can explain this situation. The increase in life expectancy and the aging of people live with HIV with the generalization of the antiretroviral treatment. This situation is accompanied by an increase in the duration of exposure to cumulative risk factors such as metabolic abnormalities and smoking [7]. Some cardiovascular risk factors are sides effects of antiretroviral treatment. Most PIs increase plasma lipid levels especially hypertriglyceridaemia and hypercholesterolemia. Non Nucleosidique Inhibitor of Reverse Transcriptase (NNIRTs) appears to increase HDL, especially Nevirapine. [7]

Diabetes is more common in patients on antiretroviral and caused by insulin resistance syndrome, in which lipodystrophy plays an important role mainly for patients [8] [9].

In Senegal, triple therapy has been accessible and free since 2003, but few studies have been conducted out on cardiovascular risk factors and particularly on hypertension in people living with HIV [6]. The objectives of this study were to determine the prevalence and the factors associated with the occurrence of hypertension in patients living with HIV followed at the Ambulatory Treatment 
Center (CTA) in Fann.

\section{Patients and Method}

\subsection{Study Framework}

The study was conducted at the Ambulatory Treatment Center (CTA), which is a national reference center for ambulatory follow-up of patients living with HIV (PLHIV).

\subsection{Type of Study}

This was a retrospective descriptive and analytical study carried out on the basis of patient records treated as outpatients at the Fann CHNU in Dakar. This study was carried out from $1^{\text {st }}$ January 1998 to $31^{\text {st }}$ December 2014.

\subsection{Sampling}

This study was conducted based on a complete sampling of all patients followed during the study period.

\subsection{Case Definition}

We referred to international standards for the diagnosis of hypertension. Patients were considered as hypertensive if their systolic blood pressure(SBP) was $\geq 140 \mathrm{mmHg}$ and/or their diastolic blood pressure(DBP) $\geq 90 \mathrm{mmHg}$ at three consecutive measurements separated by one to two weeks or if they were known to be hypertensive and were treated for it.

\subsection{Inclusion Criteria}

We included all patients who met the following criteria: Patients with confirmed HIV infection, who were at least 18 years old, hypertensive or not on ARV treatment or not.

\subsection{Description of the Survey Form}

All the collected variables are from the data extracted from the "ESOPE" database, which is software dedicated to the monitoring of PLHIV.

- Socio-demographic, clinical and biological characteristics are collected:

Age, sex, occupation, geographical origin, marital status, Hb, glycaemia, triglycerides, creatinine, CD4 count, viral load, WHO stage, opportunistic infections, ARV treatment, antihypertensive therapy...

\section{- Constraints and limitations of the study:}

This work was made difficult due to its retrospective character. Records were not always complete and blood pressure taking conditions were not specified. Some factors associated with hypertension were not been reported: lipodystrophy, fasting glucose, lipid balance, antiretroviral protocol and other personal or family cardiovascular risk factors (cardiovascular accident, smoking, diabetes ...). Some missing data were also observed. 


\subsection{Software Used for Data Capture, Retrieval and Analysis}

Data were entered using ESOPE software version 5.0. "ESOPE" is computer-based personalized software dedicated to the monitoring of PLHIV.

We extracted data from this database for the study period from January 2014 to December 2014. These data were exported to Excel and supplemented for some missing variables from file sources (A2, Os, TARV record book). Epi Info software version 3.5.3 was used for data analysis. Averages were compared using Student test and the Exact Fischer test, percentages, the $\mathrm{Chi}^{2}$ test, according to their conditions of applicability.

A value of $\mathrm{p}<0.05$ was considered significant.

Multiple logistic regression was used to identify the risk factors associated with hypertension, and give information about confounders.

\subsection{Ethical Aspects}

The study was performed on anonymous files. The identity and address of patients will remain confidential and will not be subject to any publication. We obtain patients verbal consents before inclusion in the program

\section{Results}

Of the 3624 records of patients followed at CTA in Fann and included during the study period, 1184 cases of hypertension were recorded, which represents a prevalence of $32.7 \%$.

\subsection{Characteristics of Patients with Hypertension (Table 1)}

\subsubsection{Epidemiological Characteristics}

The average age of the population in the study was 47,3 years \pm 10.5 years. The median was 47 years [ 20 years - 82 years]. The predominant age groups were 40 - 49 years $(36.23 \%)$ and 50 - 59 years $(25.1 \%)$.

Females accounted for $58.8 \%$ of the cases and the sex ratio was 0.7. Patients were mostly from Dakar (87\%). Unemployment rate was $27.7 \%$. Among the workers, those in the informal sector were the majority and accounted for $60.81 \%$.Patients married regimens were the majority (56.33\%), followed by widowed (16.38\%) and singles (15.20\%).

\subsubsection{Clinical Features}

The majority of patients have had a history of opportunistic infections (61.8\%), or sexually transmitted infections (STIs) (14.9\%).

Prurigo and oral candidiasis were the most frequent (15.3\%), followed by tuberculosis (14.9\%).

Most of patients had normal BMI (53.3\%) or underweight (26.3\%).

Stages II and III of WHO were mostly represented with $42.5 \%$ and $31.8 \%$ of cases respectively.

\subsubsection{Biological Characteristics}

HIV-1 was by far the dominant serological profile (87.6\%). 
N. F. N. Gueye et al.

Table 1. Socio-demographic, clinical and biological characteristics of patients with hypertension.

\begin{tabular}{|c|c|}
\hline Variables & Percentage \% (n) \\
\hline \multicolumn{2}{|c|}{ Age group (years) $n=1181$} \\
\hline $15-29$ years & $4.47(53)$ \\
\hline $30-39$ years & $22.38(265)$ \\
\hline $40-49$ years & $36.23(429)$ \\
\hline$>50$ years & $36.65(434)$ \\
\hline . & $0.25(3)$ \\
\hline \multicolumn{2}{|l|}{ Sex } \\
\hline Female & $58.78(696)$ \\
\hline Male & $40.96(485)$ \\
\hline $.0 .25(3)$ & \\
\hline \multicolumn{2}{|c|}{ Professional Status $n=1175$} \\
\hline Jobless & $27.7(328)$ \\
\hline Informal sector & $60.81(720)$ \\
\hline Formal Sector & $10.72(127)$ \\
\hline \multirow{2}{*}{\multicolumn{2}{|c|}{$\begin{array}{c}.0 .76(9) \\
\text { Geographic origin }\end{array}$}} \\
\hline & \\
\hline Dakar & 86.99 \\
\hline Other regions & 12.75 \\
\hline \multicolumn{2}{|l|}{$.0 .25(3)$} \\
\hline \multicolumn{2}{|l|}{ Marital status $n=1169$} \\
\hline In a relationship & $56.33(667)$ \\
\hline Divorced & $10.81(128)$ \\
\hline Widowed & $16.38(194)$ \\
\hline Single & $15.20(180)$ \\
\hline \multicolumn{2}{|l|}{$.1 .26(15)$} \\
\hline \multicolumn{2}{|l|}{ VIH Type $n=1184$} \\
\hline VIH1 & 87.6 \\
\hline VIH2 & 9.8 \\
\hline $\mathrm{VIH} 1+2$ & 2.6 \\
\hline \multicolumn{2}{|l|}{ BMI } \\
\hline$<18.5$ & 26.35 \\
\hline$[18.5-24.9]$ & 53.26 \\
\hline$\geq 25$ & 20.38 \\
\hline \multicolumn{2}{|l|}{ WHO stage } \\
\hline Stage I & 18.86 \\
\hline Stage II & 42.49 \\
\hline Stage III & 31.83 \\
\hline Stage IV & 6.83 \\
\hline \multicolumn{2}{|l|}{ CD4 count } \\
\hline $500 / \mathrm{mm}^{3}$ & 14.01 \\
\hline 350 et $499 / \mathrm{mm}^{3}$ & 12.94 \\
\hline 200 et $349 / \mathrm{mm}^{3}$ & 25.78 \\
\hline$<200 / \mathrm{mm}^{3}$ & 47.27 \\
\hline \multicolumn{2}{|l|}{ Treatment regimen } \\
\hline IP & 17.6 \\
\hline INNRT & 82.4 \\
\hline
\end{tabular}


The average CD4 count was $266 \pm 237$ cells $/ \mathrm{mm}^{3}$. The median was 214 cells $/ \mathrm{mm}^{3}$ with extremes of 1 and $1718 \mathrm{cells} / \mathrm{mm}^{3}$. The majority of patients had a CD4 count $<100$ cells $/ \mathrm{mm}^{3}$ (27.9\%), followed by those with CD4 count between 200 and $349 / \mathrm{mm}^{3}(25.78 \%)$.

\subsubsection{Therapeutic Features}

Of the 1184 hypertensive patients, 706 were on ARV therapy. $17.6 \%$ of them were under IP compared with $82.4 \%$ under INNRT.

\subsection{Associated Factors with Hypertension and ART}

No significant difference was found between hypertensive PLHIV under ARV and those who are ARV-naïve; with regard to age, sex, and marital status.

Of the non-treated hypertensive patients, $5.6 \%$ were overweight compared to $4.8 \%$ in treated hypertensive patients.

Among patients with hypertensive ARV, 59.5\% had CD4 counts below 200 / $\mathrm{mm}^{3}$ compared to $26.9 \%$ only in non-treated patients, with a very significant difference $(\mathrm{p}<0.001)$ (Table 2)

Table 2. Associated factors with hypertension and ART.

\begin{tabular}{|c|c|c|c|c|}
\hline Parameters & $\mathrm{HTA}+$ on ARV & $\begin{array}{c}\text { HTA+ without } \\
\text { ARV }\end{array}$ & $0 \mathrm{R}[\mathrm{IC}]$ & $P$ value \\
\hline Median age (year) & 47.5 & 47 & & 0.41 \\
\hline \multicolumn{5}{|l|}{ Sex $(\%)$} \\
\hline Female & 59.9 & 55.9 & $0.8[0.7-1.1]$ & 0.2 \\
\hline Male & 40.1 & 40.1 & & \\
\hline \multicolumn{5}{|l|}{ Marital status (\%) } \\
\hline Yes & 45.7 & 40.6 & $0.8[0.6-1]$ & 0.08 \\
\hline No & 59.4 & 54.2 & & \\
\hline \multicolumn{5}{|l|}{$\mathrm{CD} 4\left(/ \mathrm{mm}^{3}\right)$} \\
\hline$<200$ & 59.5 & 26.9 & $0.1[0.07-0.2]$ & $10^{-10}$ \\
\hline [200 - 499] & 35.7 & 43 & & \\
\hline$\geq 500$ & 4.7 & 30.1 & & \\
\hline
\end{tabular}

\subsection{Comparison between Hypertensive and Non-Hypertensive PLHIV (Table 3)}

Compared to non-hypertensive PLHIV, Hypertensive cases had significantly:

- A higher average of age (47.3 years versus 43.3 years), with $\mathrm{p}<0.001$.

- A higher average of BMI $(\mathrm{p}<0.001)$

- A stages I and II of WHO ( $p<0.001)$

- An antiretroviral therapy $(\mathrm{p}<0.001)$

No difference was noted for the sex, the serotype and the type of ARV. 
Table 3. Associated factors with hypertension among HIV infected patients.

\begin{tabular}{|c|c|c|c|c|}
\hline Parameters & HTA+ & HTA- & oR [IC] & Value of $p$ \\
\hline Average age (years) & 47.3 & 43.3 & $1.05[1.04-1.05]$ & $10^{-6}$ \\
\hline \multicolumn{5}{|l|}{ Sex $(\%)$} \\
\hline Female & 58.3 & 56.8 & $0.8[0.7-0.9]$ & 0.4 \\
\hline Male & 41.7 & 43.2 & & \\
\hline Average BMI $\left(\mathrm{kg} / \mathrm{m}^{2}\right)$ & 21.6 & 19.3 & $5.3[3.3-8.5]$ & $10^{-5}$ \\
\hline \multicolumn{5}{|l|}{ WHO stage (\%) } \\
\hline I-II & 60.7 & 53.4 & $1.4[1.2-1.4]$ & 0.00003 \\
\hline III-IV & 39.3 & 46.6 & & \\
\hline \multicolumn{5}{|l|}{ Serotype (\%) } \\
\hline HIV-1 & 86.2 & 87.9 & $0.9[0.7-1.1]$ & 0.2 \\
\hline HIV $2+/-1$ & 13.8 & 12.1 & & \\
\hline \multicolumn{5}{|l|}{ ARV Rate (\%) } \\
\hline Yes & 59.6 & 36.6 & $2.5[1.7-3.7]$ & $10^{-6}$ \\
\hline No & 40.4 & 63.4 & & \\
\hline \multicolumn{5}{|l|}{ ARV plan (\%) } \\
\hline INNUC & 90.9 & 92.9 & $0.9[0.6-1.4]$ & 0.9 \\
\hline IP & 9.1 & 7.1 & & \\
\hline \multicolumn{5}{|l|}{ Deaths (\%) } \\
\hline Yes & 10.6 & 14 & $0.6[0.5-0.8]$ & $10^{-6}$ \\
\hline No & 89.4 & 85.9 & & \\
\hline
\end{tabular}

\section{Discussion}

\subsection{Epidemiological Aspects}

The prevalence of hypertension in the cohort was $32.7 \%$. This prevalence is higher than those described in others cohort studies such as DAD multicentric study (23.8\%) [10] [11] and especially APROCCO [9] in France (5.2\%). The prevalence of hypertension in HIV-infected individuals in industrialized countries ranges from $5.2 \%$ to $34.2 \%$ [4]. This prevalence is likely to be overestimated due to the lack of rigorous adherence to optimal conditions for PI in patients. However, a recent Senegalese study observed $28.1 \%$ of hypertensive patients [12]. This difference can be explained by the higher average age in our study.

We found a prevalence of $36.6 \%$ in the group of patients without ARV treatment and $59.6 \%$ in patients with ARV. In a previous study in Senegal, this difference was $21 \%$ vs $34.7 \%$ [12]. A Norwegian study also found a difference between the two groups, with $13 \%$ of hypertension in ARV naïve patients compared to $21 \%$ in ARV patients [4]. ARV therapy would be a factor favoring the occurrence of hypertension in PLHIV.

The average age of our population was 47 years and the majority of cases were 
above 40 years $(73 \%)$. This average age is similar to that observed by DIOUF Assane et al. [13]. Our study population belongs to one of the oldest PLHIV cohorts in Senegal. This high age average reflects the fact that the population of PLHIV followed in our cohort is getting older. Patients infected with HIV also have early aging with an advance of $10-15$ years compared to their biological age.

Female predominance (58.8\%) noted in our study was not observed in other studies of cardiovascular risk factors in people living with HIV. A study conducted by Bergersen et al. [5] in Norway highlighted a male predominance in treated patients $(81 \%)$ or untreated patients $77 \%$. This difference is due to the predominance transmission through homosexual sex relation in these countries, whereas heterosexual transmission is more frequent in Senegal. Female predominance is usually noted in studies in Africa [14]. The fact that vulnerability is mostly anatomical, biological and above all socio-cultural in our regions, explain these results.

\subsection{Clinical Aspects}

The associated cardiovascular risk factor confirmed in our patients was diabetes (1.7\%). This prevalence is comparable with the results of other cohorts of PLHIV who had 2\% diabetes in Senegal and Norway [5] [6].

In our baseline study, $6.4 \%$ had a BMI $>30$. In the DAD study, the prevalence of obesity (5.2\%) was close to ours. Indeed, the conditions for putting under ARV are all the earlier as the immune deficiency is severe and the cachectic syndrome ranked at WHO stage IV. It would have been more interesting to benefit from the BMI at the time of diagnosis of hypertension.

\subsection{Paraclinical Aspects}

The most frequent serological profile in our patients was HIV-1 (87.6\%) and the difference was not significant compared to non-hypertensive patients. This serotype predominates in studies carried out in Senegal [13]. Nevertheless, hypertension was more frequent in patients with a double profile or in patients with HIV-2 LEYE AW F found a higher Framingham score for HIV-2 [6]. This increase in cardiovascular risk is related to the fact that these patients infected with HIV-2 were in most cases under IP.

\subsection{Therapeutic and Evolutionary Aspects}

We have noticed that antiretroviral therapy was associated with a significantly higher frequency of hypertension with an $\mathrm{OR}=2.5$. This observation was also made in other studies such as the "multicenter AIDS cohort study" which found a risk of developing hypertension with an $\mathrm{OR}=1.7$. Such a risk occurs from the second year of exposure to ARV. A variant of the DAD study also found $6.1 \%$ hypertension in naïve subjects versus $10.1 \%$ in treated patients. [4]

Hypertensive patients under PI (9.1\%) are more numerous than hypertensive patients with NNRTI (7.1\%) with no statistically significant difference $(\mathrm{p}=0.1)$. 
The responsibility for anti-protease inhibitors in the occurrence of hypertension is essential and remains a shared question. These molecules (especially lopinavir, ritonavir) increase plasma lipid levels (total cholesterol, LDL cholesterol, triglycerides), with the remarkable exception of saquinavir and atazanavir [7]. Indinavir is the anti-protease most commonly associated with hypertension. A study found that the prevalence of HTA was $29 \%$ in patients treated with indinavir against none of the patients treated with nelfinavir, saquinavir, ritonavir [15]

However, the HOPS study (HIV Outpatient Study) confirmed a very significant association between cardiovascular events and PI treatment with $\mathrm{OR}=4.9$ [95\% CI: 1.2 - 32.3] in 5672 patients. This was attenuated after adjustment to traditional risk factors (age, sex, hypertension, tobacco, diabetes, dyslipidemia), suggesting that NPs had no independent effect on cardiovascular risk. Likewise, the Kaiser Permanente Study retrospectively analyzed the rate of hospitalizations for coronary artery disease in HIV+ and HIV-treated patients. The rate of hospitalizations was higher in HIV infected than in HIV negative (6.5 vs 3.8/1000 patient-years, $\mathrm{p}<0.01$ ), but within HIV+ it was identical in the treated and untreated patients [7]. LEYE AW F [6] found fewer hypertensive patients under PI (21.4\% versus $28.2 \%$ without PI).

The lethality was significantly lower in the hypertensive group (10.6\%) compared to the control groups $(14 \%)$ with $p<0.001$. The leading causes of death were mostly due to frequent opportunistic infections in stages III-IV, which predominated in non-hypertensive subjects. Moreover, malnutrition, which is an important factor of death in PLHIV, was more prevalent among non-hypertensive subjects in our cohort.

\section{Conclusion}

The widespread availability of antiretroviral in low-income countries has resulted in the improvement of life quality and life expectancy among people living with HIV (PLHIV). However, numerous studies have highlighted the occurrence of cardiovascular risk factors related to antiretroviral therapy, mainly based on PI. The highest frequency of cardiovascular disease risk, particularly myocardial infarction in HIV-infected patients treated with antiretroviral; compared to HIV-positive patients under ARV and the non-infected population, has been established. Dyslipidemia due to antiretroviral therapy, behavioral factors (smoking) and specific effects associated with HIV infection are said to be the mostly implicated risk factors.

\section{Declaration of Absence of Conflict of Interest}

The authors report no conflict of interest.

\section{Authors' Contributions}

NGOM GUEYE Ndeye Fatou, Aissata GUINDO, Noel Magloire Manga design, data collection, statistical analysis and manuscript review. Other authors: design and manuscript review. All the authors have read and approved the final version 
of the manuscript.

\section{Acknowledgements}

We thank all the patients and staff who participated in the study.

\section{References}

[1] ONUSIDA (2012) Le point sur l'épidémie. Rapport ONUSIDA sur l'épidémie mondiale de SIDA en 2012. http://www.unaids.org/en/media/unai

[2] Kramoh, E.K., N’Goran, Y.N.K., Akie-Trabousi, E., et al. (2011) Hypertension Management in an Outpatient Clinic at the Institute of Cardiology of Abidjan (Ivory Coast). Archives of Cardiovascular Diseases, 104, 558-564. https://doi.org/10.1016/j.acvd.2011.08.002

[3] Yayehd, K., Damorou, F., Akalkpo, R., et al. (2011) Prévalence de l'hypertension artérielle et description de ses facteurs de risque à Lomé (Togo): Résultats d'un dépistage réalisé dans la population générale en mai 2011. Annales de Cardiologie et d'Angéiologie.

[4] Bernardino De La Serna, J.I., Zamora, F.X., Montes, M.L., et al. (2008) Hipertension arterial, infeccion por el virus de la inmunodeficiencia humana y tratamiento antiretrovirico de gran actividad. Enfermedades Infecciosas y Microbiología Clínica, 28, 32-37. https://doi.org/10.1016/j.eimc.2008.07.005

[5] Bergersen, B.M., Sandvik, L., Dunlop, O., et al. (2003) Prevalence of Hypertension in HIV-Positive Patients on Highly Active Antiretroviral Therapy (HAART) Compared with HAART Naive and HIV-Negative Controls: Results from a Nowegian Study of 721 Patients. European Journal of Clinical Microbiology \& Infectious Diseases, 22, 731-736. https://doi.org/10.1007/s10096-003-1034-z

[6] Leye, A.W.F. (2012) Les facteurs de risque cardiovasculaires chez les patients vivant avec le VIH: Etude multicentrique à propos de 133 cas. Thèse Méd, Dakar, No. 91.

[7] Chironi, G., Simon, A. and Vittecoq, D. (2004) Le risque cardiovasculaire au cours des traitements antirétroviraux. Médecine Thérapeutique, 10, 120-128.

[8] Gallet, B., Chedin, P. and Pulik, M. (1999) Complications cardiovasculaires chez les patients infectés par le VIH: Les antiprotéases sont-elle en cause? Sang Thrombose Vaisseaux, 11, 511-516.

[9] Saves, M., Chene, G., Ducimetiere, P., et al. (2003) Risk Factors for Coronary Heart Disease in Patients Treated for Human Immunodeficiency Virus Infection Compared with the General Population. Clinical Infectious Diseases, 37, 292-298. https://doi.org/10.1086/375844

[10] Capeau, J., Bouteloup, V., Katlama, C., et al. (2012) Ten-Year Diabetes Incidence in 1046 HIV-Infected Patients Started on a Combination Antiretroviral Treatment. AIDS, 26, 303-314. https://doi.org/10.1097/QAD.0b013e32834e8776

[11] Friis-Moller, N., Reiss, P., Sabin, C.A., et al. (2007) Class of Antiretroviral Drugs and the Risk of Myocardial Infarction. The New England Journal of Medicine, 356, 1723-1735. https://doi.org/10.1056/NEJMoa062744

[12] Mbaye, M.N., Niang, K., Sarr, A., Mbaye, A., Diedhiou, D., Ndao, M.D. et al. (2011) Aspects épidémiologiques du diabète au Sénégal: Résultats d'une enquête sur les facteurs de risque cardiovasculaire dans la ville de Saint-Louis. Médecine des Maladies Métaboliques, 5, 659-664. https://doi.org/10.1016/S1957-2557(11)70343-1

[13] Diouf, A., Cournil, A., Ba-Fall, K., Ngom-Gueye, N.F., Eymard-Duvernay, S., 
Ndiaye, I., et al. (2012) Diabetes and Hypertension among Patients Receiving Antiretroviral Treatment Since 1998 in Senegal: Prevalence and Associated Factors. International Scholarly Research Network, 2012, Article ID: 621565.

[14] Coulibaly, A.M. (2013) Mortalité sous trithérapie ARV: Prévalence et facteurs associés chez les patients infectés par le VIH sous traitement ARV de lère ligne suivi au CTA du CHUN de Fann Thèse Méd, Dakar, No. 1.

[15] Hewitt, R.G., Thompson IV, W.M., Chu, A., et al. (2001) Indinavir not Nelfinavir, Is Associated with Systemic Hypertension When Compared to No Protease Inhibitor Therapy. The International AIDS Conference, Chicago, Abstract No. 658.

\section{Submit or recommend next manuscript to SCIRP and we will provide best} service for you:

Accepting pre-submission inquiries through Email, Facebook, LinkedIn, Twitter, etc. A wide selection of journals (inclusive of 9 subjects, more than 200 journals)

Providing 24-hour high-quality service

User-friendly online submission system

Fair and swift peer-review system

Efficient typesetting and proofreading procedure

Display of the result of downloads and visits, as well as the number of cited articles

Maximum dissemination of your research work

Submit your manuscript at: http://papersubmission.scirp.org/

Or contact health@scirp.org 